\title{
ESTUDO NA INFLUÊNCIA DO REFINO DE MALHA PARA UM FORNO DE CRAQUEAMENTO TÉRMICO
}

\author{
T. S. MOREIRA ${ }^{1}$, J. M. de OLIVEIRA Jr ${ }^{1}$, R. F. VIANNA ${ }^{1}$ e J. L. G. MARINHO ${ }^{2}$ \\ ${ }^{1}$ Universidade Federal da Bahia, Departamento de Pós-graduação de Engenharia Química \\ ${ }^{2}$ Universidade Federal de Alagoas, Departamento de Engenharia de Química \\ E-mail para contato: tiagosmmoreira@gmail.com
}

\begin{abstract}
RESUMO - Os fornos de craqueamento térmico tem uma grande importância na cadeia petroquímica, principalmente nos setores da primeira e da segunda geração desse ramo industrial. Setores esses que geram insumos básicos para fibras, resinas, plásticos e produtos químicos. Seu funcionamento é baseado na quebra de grandes hidrocarbonetos, utilizando para isto grandes variações de pressão e temperatura via reação química. Visando uma melhor compreensão deste fenômeno, esse trabalho tem como proposta analisar o refinamento da malha para o estudo de fluidodinâmica da combustão na seção de radiação de um forno de craqueamento térmico, utilizando o aplicativo computacional ANSYS CFX 13. Foi desenvolvido um modelo 3-D, onde houve a implementação das equações de conservação de massa, movimento e energia em conjunto com a equação de reação de combustão e transferência de calor por radiação. Os resultados apresentam análises quantitativas das temperaturas médias e o esforço computacional envolvido para o refinamento de malha.
\end{abstract}

\section{INTRODUÇÃO}

Os grandes fornos a gás têm várias aplicações nas indústrias petroquímicas e indústrias para produção de energia. A mais importante da aplicação na indústria petroquímica é craqueamento térmico de hidrocarbonetos para produção de olefinas, diolefinas e aromáticos, onde tem sido mostrado (Habibi et al., 2007).

No craqueamento térmico é utilizado o forno de craqueamento como principal equipamento, com influencia na eficiência do rendimento, seletividade para produtos importantes e consumo de energia no equipamento, mostrado (Qian, 2003).

O processo de craqueamento térmico ou pirólise é a conversão de uma substância em outra por meio do uso de calor, isto é, pelo aquecimento da substância na ausência de ar ou oxigênio a temperaturas que podem chegar a $450^{\circ} \mathrm{C}$, tem sido mostrado (Weisz et al., 1979).

Para entender melhor como ocorre o processo de pirólise dentro de uma fornalha de craqueamento térmico, utilizou-se técnicas de Fluidodinâmica Computacional (CFD Computacional Fluid Dynamics) que é um conjunto de ferramentas numéricas e computacionais utilizadas para resolver, visualizar e interpretar a solução das equações de balanço de massa, momento e energia, sendo capaz de reproduzir e prever fenômenos físicos e físico-químicos que ocorrem em um dado escoamento. Atualmente, está recente ferramenta 


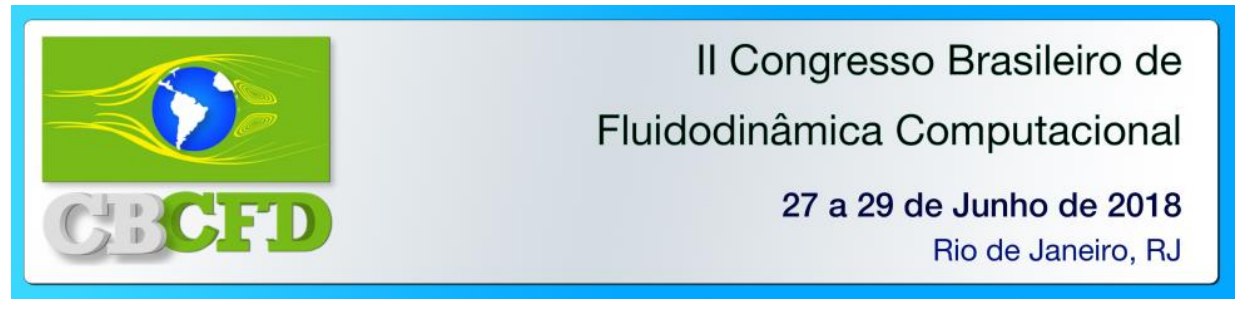

vem sendo cada vez mais difundida em muitas aplicações na indústria química, petroquímica e petróleo e gás.

A malha computacional é uma representação ou a discretização do plano físico utilizado na simulação. A representação tem suas coordenadas são identificadas ao computador, que automaticamente são lidas formando malha computacional da geometria, mostrado (Maliska, 2004).

O trabalho tem como motivo a elaboração de uma representação real de um forno de craqueamento térmico, para fazer estudo de refinamento de malha, na qual a malha ideal será utilizada como ferramenta de estudo para os fenômenos que envolvem o equipamento.

\section{METODOLOGIA}

O estudo foi baseado em um equipamento industrial através das suas medidas de projeto, apenas sua seção radiante, onde encontrasse 10 queimadores alinhados em 4 fileiras em cada lado do forno. Internamente existe o reator tubular, onde sua entrada de produto se dá pelo topo e sua saída na base do equipamento, fazendo curvas na tubulação do reator, conforme mostra a Figura 1.

A malha utilizada foi não-estruturada, mostrada na Figura 1, com o formato tetraédrico por ter uma melhor adequação nas superfícies não uniformes e também por não demandar um esforço computacional grande, mostrados (Çencel e Cimbala, 2012). O número total de elementos foi variado quatro vezes, de 1,5 milhões, 3,1 milhões, 5,4 milhões e 8,9 milhões. $\mathrm{Na}$ modelagem proposta para o presente estudo foram utilizadas as equações de massa, quantidade de movimento e energia, estado de simulação estacionário, efeitos gravitacionais, de turbulência, coordenadas cartesianas e propriedades dos fluidos constantes e também considerando os seguintes fenômenos: reação química de combustão através do modelo Eddy Dissipation, transferência de calor por radiação através do modelo P 1 (que é um modelo de aproximação direcional onde adota a intensidade de radiação sendo isotrópica), e o modelo de turbulência k- $\varepsilon$. Nesta modelagem foi adotado um modelo de mistura utilizando a formulação Euleriana-Euleriana.
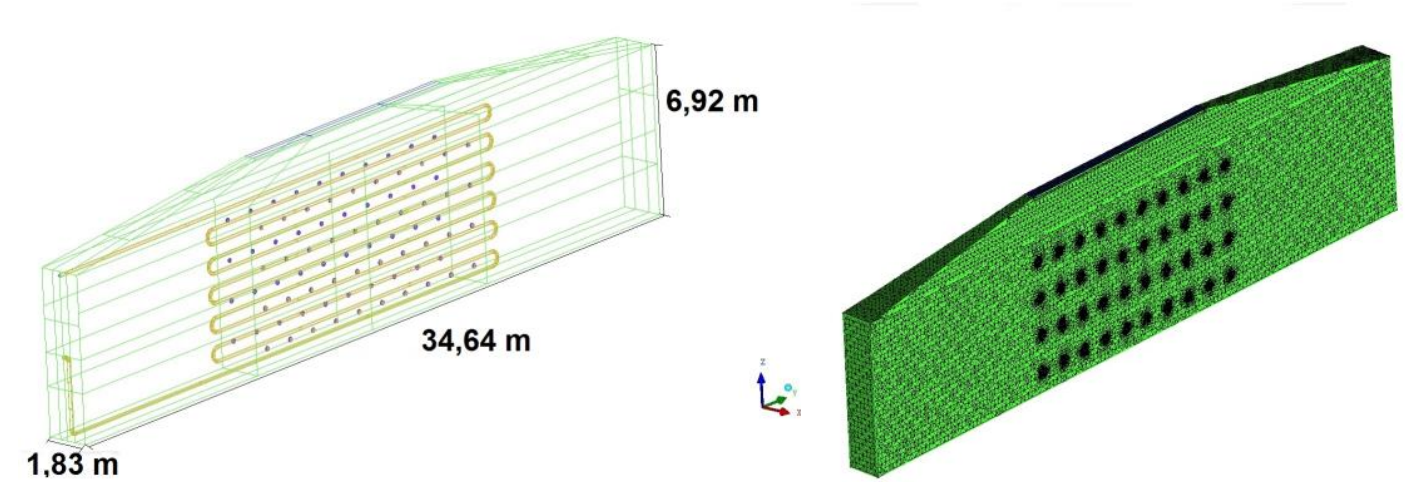

ANSYS

Figura 1 - Representação e malha da câmera de radiação do forno. 


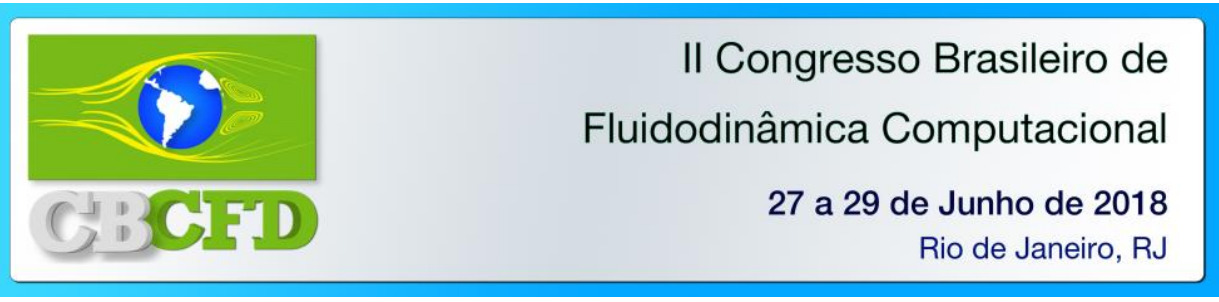

$\mathrm{Na}$ simulação foi utilizado como gás combustível o metano e como oxidante o ar e utilizando as seguintes condições de contorno, conforme a Tabela 1.

Tabela 1 - Condições iniciais de velocidade.

\begin{tabular}{|c|c|c|}
\hline Fileira & Valor de metano $(\mathrm{m} / \mathrm{s})$ & Valor de ar $(\mathrm{m} / \mathrm{s})$ \\
\hline $1^{\mathrm{a}}$ & 50,00 & 57,50 \\
\hline $2^{\mathrm{a}}$ & 37,50 & 43,13 \\
\hline $3^{\mathrm{a}}$ & 25,00 & 28,75 \\
\hline $4^{\mathrm{a}}$ & 25,00 & 28,75 \\
\hline
\end{tabular}

\section{RESULTADOS}

Para uma análise dos dados, foram comparados três diferentes planos, onde foi calculada a temperatura média de cada plano, conforme o Figura 2.

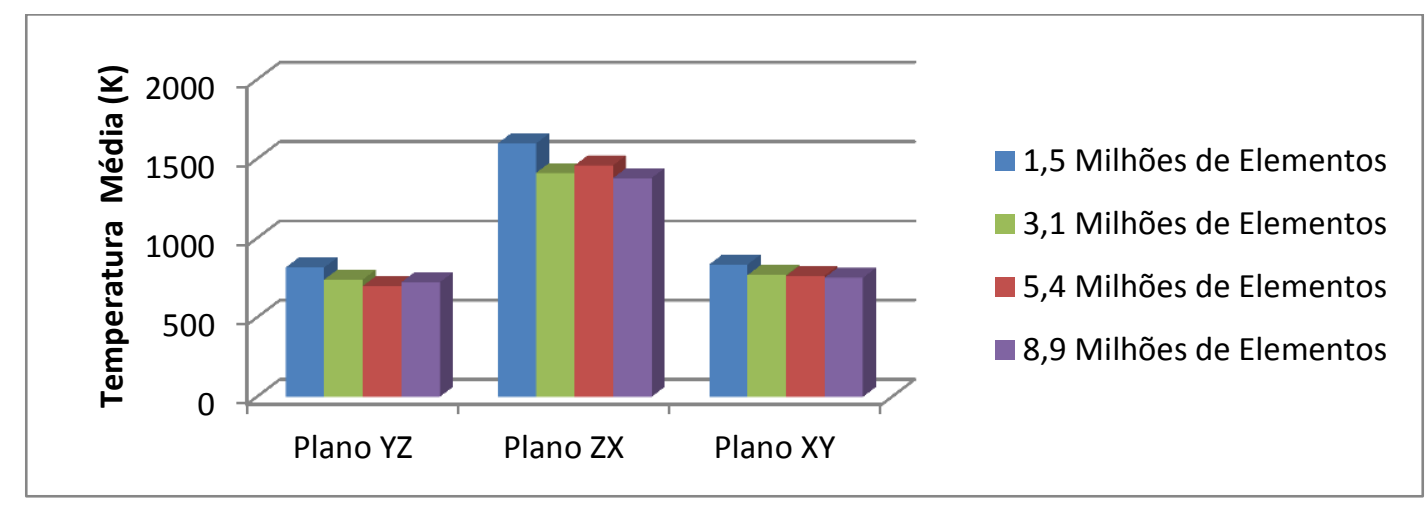

Figura 2 - Gráfico do número total de elementos com suas temperaturas médias em cada plano.

Na Figura 2 mostra as temperaturas médias em cada plano para cada número de elementos. Através da Figura 2 é possível observar que no plano YZ a medida do número de elementos cresce e a temperatura média diminui até 5,4 milhões de elementos. Para a malha de 8,9 milhões de elementos ficou entre as malhas de 3,1 milhões e 5,4 milhões de elementos. No plano ZX, a malha que teve menor número de elementos, obteve a temperatura média maior. Já a malha de 5,4 milhões elementos foi levemente maior à temperatura média do que a malha de 3,1 milhões de elementos e a malha de 8,9 milhões de elementos teve o menor resultado. No plano XY, a temperatura média decresceu à medida que o número total de elementos cresce, mesmo que a diferença entre 3,1 milhões, 5,4 milhões e 8,9 milhões de elementos for levemente perceptível. 


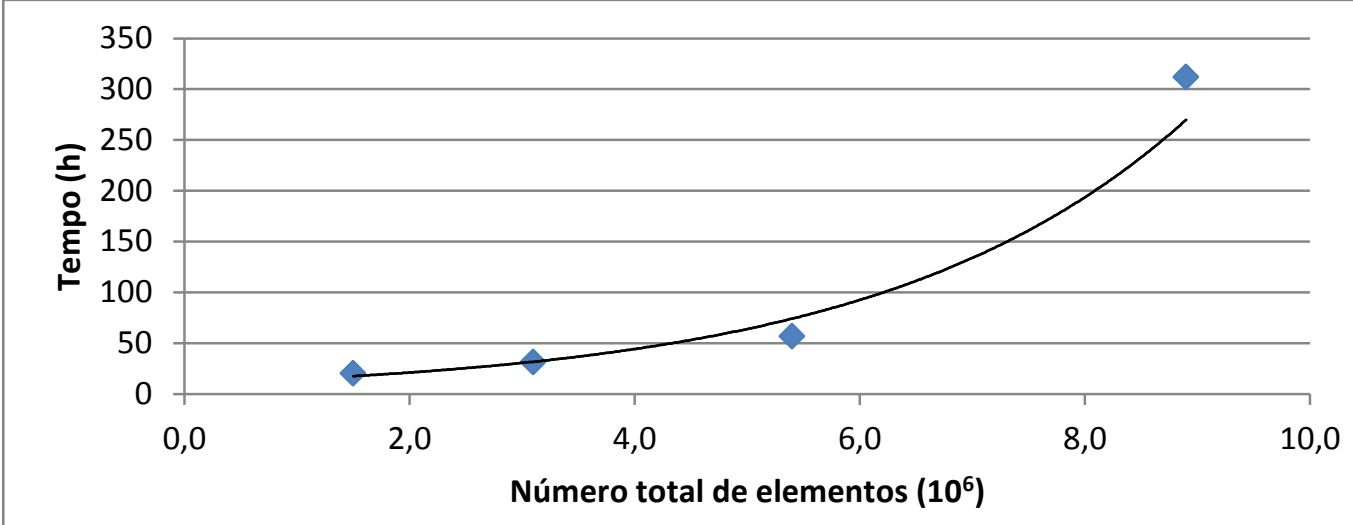

Figura 3 - Gráfico do número total de elementos com o tempo de processamento.

A Figura 3 mostra o tempo computacional à medida que aumenta o número total de elementos. Então à medida que o número total de elementos aumenta, o tempo computacional aumenta de uma forma exponencial. Já era esperado que à medida que o número de elementos aumenta, o esforço computacional aumenta, acarretando assim em um tempo de processamento maior.

\section{CONCLUSÕES}

O estudo do refinamento de malha é fundamental para analisar a viabilidade do estudo de CFD, mediante disso, foi possível observar que a malha de 3,1 milhões de elementos obteve resultados de temperaturas médias próximas com relação à malha de maior valor e com menor esforço computacional com relação às demais malhas mais refinadas.

\section{REFERENCIAS}

ÇENGEL, Y. A.; CIMABALA, J. M. Mecânica dos Fluidos: Fundamentos e Aplicações, AMGH Editora, $1^{\text {a }}$ Ed., 2012

HABIBI, A.; MERCI, B.; HEYNDERICKX, G. J. Impact of radiation in CFD simulations of steam cracking furnaces. Computers \& Chemical Enginnering, v 31, p. 1389 - 1406, 2007.

MALISKA, C. R.; Transferência de Calor e Mecânica dos Fluidos Computacional, LTC Editora, 2a Ed., 2004.

QIAN, J. L. Tubular Heating Furnace, China Petrochemical Press, Beijing, 2003.

WEISZ, P. B.; HAAG, W. O.; RODEWALD, P. G. Catalytic production of high-grade fuel (gasoline) from biomass compounds by shape-selective catalysis. Science, 1979.

\section{AGRADECIMENTOS}

Os autores gostariam de agradecer à $\mathrm{CNPq}$ pelo apoio financeiro e ao Laboratório de Sistemas de Separação e Otimização de Processos (LASSOP - UFAL) por todo suporte fornecido para a execução deste trabalho. 